\title{
Ovarian granulosa cell tumor and clomiphene citrate resistance. A case report and review of the literature
}

\author{
Olga Triantafyllidou ${ }^{1}$, George Sigalos ${ }^{1}$, Irida Oikonomou ${ }^{2}$, Nikos Vlahos ${ }^{3}$ \\ ${ }^{1}$ Reproductive Medicine Unit, "Leto" Maternity Hospital, Athens, Greece. \\ ${ }^{2}$ Medical school, University of Athens, Greece. \\ ${ }^{3} 2^{\text {nd }}$ Department of Obstetrics and Gynecology, "Aretaieion" Hospital, University of Athens, Greece.
}

\begin{abstract}
Granulosa cell tumors (GCTs) account for less than 5\% of all ovarian malignancies, occur in younger ages, are usually diagnosed in their early stages, and have a good prognosis. GCTs usually present with features of hyperestrogenism. This paper reports the unusual case of an adult with a GCT with manifestations including amenorrhea, mild hirsutism, infertility, clomiphene citrate (CC) resistance (CC), mildly elevated testosterone, high anti-Müllerian hormone $(\mathrm{AMH})$ and normal estrogen levels. The patient was initially diagnosed with polycystic ovarian syndrome (PCOS), and after four attempts at ovarian stimulation she was diagnosed with $\mathrm{CC}$ resistance. The patient later underwent laparoscopic evaluation on account of a solid mass on her left ovary. The pathology report described it as a borderline adult type GCT and four weeks after surgery she had a positive pregnancy test. Twelve months after delivery, the patient had no obvious symptoms of disease and her menstrual cycle was normal. Serial measurements of serum inhibin $\mathrm{B}, \mathrm{AMH}$, estrogen, and testosterone levels were within normal range. In conclusion, the resistance to clomiphene manifested by the patient might be explained by a potential mechanism implicating inhibin $\mathrm{B}$ and $\mathrm{AMH}$ due to the presence of a GCT. Further studies are required to evaluate the role of $\mathrm{AMH}$ and Inhibin $\mathrm{B}$ in the mechanism of $\mathrm{CC}$ resistance in women with PCOS.
\end{abstract}

Keywords: granulosa cell tumor, sex-cord ovarian tumor, clomiphene resistance, infertility

\section{INTRODUCTION}

Granulosa cell tumors (GCTs) constitute more than $70 \%$ of sex cord-stromal tumors, but account for less than $5 \%$ of all ovarian malignancies (Pectasides et al., 2008; Ugianskiene et al., 2014). GCTs appear in two different histological types: adult (AGCT) and juvenile (JGCT), which differ in histopathology, clinical presentation, and prognosis. AGCTs are far more common, accounting for $95 \%$ of all GCTs; they are usually diagnosed in perimenopausal and postmenopausal women aged 50-55 years. JGCTs are rare tumors, representing only $5 \%$ of all GCTs, and affect mostly premenarcheal girls and young women (Ugianskiene et al., 2014; Bryk et al., 2015). When compared to epithelial ovarian tumors, GCTs occur in younger individuals, are usually diagnosed in earlier stages, and offer a significantly better prognosis with long-term disease-free survival rates of up to $90 \%$ (Schumer \& Cannistra, 2003). According to recent data from Surveillance, Epidemiology and End Results (SEER), nearly $57 \%$ of GCTs are stage I tumors and may therefore be managed surgically, with the intent of completely resecting the tumor (Schumer \& Cannistra, 2003; Piura et al., 1994; Kottarathil et al., 2013).

GCTs usually present with features of hyperestrogenism. Therefore, symptoms usually revolve around altered menstrual patterns $(32.8 \%)$ including menorrhagia, metrorrhagia or irregular vaginal bleeding (Ranganath et al., 2008; Koukourakis et al., 2008). Postmenopausal bleeding is the most common finding in the postmenopausal age group; association with endometrial hyperplasia occurs in $25-50 \%$ of the cases (Schumer \& Cannistra, 2003).

This report described an unusual case of AGCT presenting with amenorrhea, infertility, clomiphene citrate (CC) resistance, and normal estrogen levels.

\section{CASE REPORT}

A 32-year-old Caucasian woman came to our service with complaints of amenorrhea and infertility. She had a history of two previous failed attempts at ovarian stimulation with CC. She had been successfully treated for amenorrhea with progestin (norethisterone $5 \mathrm{mg} /$ day, Primolut, Bayer, Germany) for 10 days in a monthly fashion.

Clinical examination revealed mild hirsutism (upper lip, chin, and upper abdominal area) without other signs of virilization (she was not assigned a Ferriman-Gallwey score due to extensive use of laser for hair removal). Pelvic examination did not reveal clitoromegaly. Her uterus and adnexa were of normal size. Transvaginal ultrasound evaluation confirmed the above findings; no signs of polycystic morphology were seen in her ovaries. A uterine septum was suggested and confirmed by hysterosalpingography (HSG). Her partner's semen parameters were normal. Hormonal analysis on day 3 of her menstrual cycle showed the following: estradiol 38pg/ml; FSH $3.6 \mathrm{IU} / \mathrm{l}$; testosterone $68 \mathrm{ng} / \mathrm{dl}$ (normal range 5-52ng/dl); LH $22.8 \mathrm{IU} / \mathrm{l}$; and Anti-Müllerian hormone (AMH) 179pmol/l. A possible diagnosis of polycystic ovarian syndrome (PCOS) based on the Rotterdam criteria was considered (Rotterdam ESHRE/ASRM-Sponsored PCOS Consensus Workshop Group, 2004).

After hysteroscopic resection of the septum, the patient proceeded with two additional ovarian stimulation cycles with clomiphene citrate $100 \mathrm{mg} /$ day (Clomiphene citrate, Anfarm Hellas, Greece) for 5 days (from day 3 to day 7) with no response. Ultrasound examination performed after the last attempt indicated her left ovary was mildly enlarged possibly because of a solid mass. Contrast-enhanced magnetic resonance imaging (MRI) scans confirmed the presence of an irregular, solid mass with a diameter of $36 \mathrm{~mm}$ within the substance of the left ovary without additional findings. Tumor markers (CA125: 14.7 $\mathrm{U} / \mathrm{ml}$, CEA: $1.5 \mathrm{ng} / \mathrm{ml}$, aFP: $4.0 \mathrm{ng} / \mathrm{ml}$ ) were within normal range.

Laparoscopic examination showed her left ovary was enlarged, with no obvious surface anomalies. After peritoneal washing cytology, her ovary was bivalved to reveal a well-defined solid mass that was easily separated from the surrounding ovarian tissue. The surface of the tumor was yellowish and friable. The tumor was removed and contained in an endobag. Her right ovary and both fallopian tubes were normal. No other signs of disease were noted in the peritoneal cavity and the procedure was completed. 
The pathology report described a borderline adult GCT. Staining by immunohistochemistry was positive for inhibin and partly positive for calherin. Nearly $10 \%$ of the cells stained positive for proliferation marker Ki-67. Examination with a microscope showed 0-2 mitoses per 10 high power field. Inhibin B serum levels measured upon histological confirmation two weeks after the procedure were within normal range $(20 \mathrm{pg} / \mathrm{ml})$.

The patient was informed of the pathology results and was scheduled for surgical staging. On the day of the procedure, the patient had a positive pregnancy test confirmed by serum $\beta-h C G$, and the procedure was cancelled. A singleton viable pregnancy was confirmed by ultrasound examination two weeks later. The patient was advised to proceed with surgical staging, with a tentative date for the procedures somewhere around the $12^{\text {th }}$ week of gestation. The risks and benefits were explained to her, but she refused to carry on with it. During her pregnancy she had serial ultrasound images of her ovaries taken along with measurements of inhibin B serum levels, which remained within normal levels. The patient underwent a planned cesarean section under epidural anesthesia at 40 weeks of gestation. During the procedure there was no macroscopic evidence of recurrent disease on her left ovary or anywhere else in the peritoneal cavity. Complete surgical staging, including peritoneal washings, left adnexectomy, exploration of peritoneal cavity, multiple peritoneal biopsies, and omentectomy were performed. Cytology and histology tests were negative for disease.

Twelve months after delivery the patient had no obvious symptoms of disease and her menstrual cycle was normal. Serial measurements of serum inhibin $B, A M H$, estrogen, and testosterone levels were within normal range.

\section{DISCUSSION}

Granulosa cell tumors (GCTs) originate from somatic cells of the sex cords of the ovary. Major functions of the granulosa cells include production of sex steroids and various other peptides required for folliculogenesis and ovulation (Kottarathil et al., 2013). Ovarian GCTs are categorized as sex cord-stromal tumors and behave as borderline malignant tumors (Pectasides et al., 2008; Fox et al., 1975). The 10-year survival rate of patients with early stage (I or II) disease is excellent (up to $90 \%$ ), while prognosis is less favorable for women with late stage disease, with 10 -year survival rates at $50-65 \%$ for stage II disease and $17-33 \%$ for disease stages III and IV (Schumer \& Cannistra, 2003). Late recurrence - 20 to 30 years after initial surgery - is one of the characteristic features of GCTs (Zhang et al., 2007).

GCTs are often hormonally active tumors and may secret estrogen, inhibin (especially the beta subunit), and $\mathrm{AMH}$, since these are normally produced by granulosa cells. Inhibin is produced in small preantral and antral follicles (Danforth et al., 1998). Lappöhn et al. (1989) first demonstrated the efficacy of inhibin B as a marker for both primary and recurrent disease and showed that increased inhibin B levels may predate clinical recurrence by up to 20 months. Following complete surgical removal of the tumor, inhibin levels are expected to fall to normal range within one week (Koukourakis et al., 2008). Elevated serum AMH levels are also highly specific for GCTs (Koukourakis et al., 2008). AMH - a product of granulosa cells in the preantral and small antral follicles - inhibits primordial follicle recruitment and the responsiveness of growing follicles to Follicle-Stimulating Hormone (FSH) (Zahid, 2014). AMH may also predate clinical recurrence by up to 11 months (Koukourakis et al., 2008). Several studies described AMH as a reliable tumor marker for either diagnosis or recurrent disease, with sensitivities ranging between $76 \%$ and $100 \%$
(Long et al., 2000; Chang et al., 2009). Further studies are required to define which tumor markers are more reliable to detect and manage GCTs. In rare cases of androgen secreting GCT, as in our case (testosterone levels were slightly elevated, $68 \mathrm{ng} / \mathrm{dl}$ ), patients may present with symptoms mimicking PCOS syndrome such as hirsutism and amenorrhea.

GCTs usually present as large unilateral masses (Ranganath et al., 2008). Radiological criteria suggestive of malignant ovarian masses include thick, irregular walls, and septa; papillary projections and solid echogenic foci (Jeong et al., 2000). An enlarged uterus with a thickened endometrium is often seen on account of the effect of estrogen. The incidence of peritoneal spread is low and tumors are rarely bilateral. Symptoms are usually nonspecific and include abdominal pain (41.1\%) and distension $(26.4 \%)$ or are associated with hyperestrogenism (menorrhagia, irregular menstrual bleeding) (Ranganath et al., 2008). Infertility may occur secondary to high inhibin levels. GCTs occasionally have a Sertoli-Leydig cell component and produce androgens, which may cause virilizing symptoms (Koukourakis et al., 2008).

Surgery remains as the method of choice to manage GCTs. The steps and principles of surgical staging are the same for all borderline ovarian tumors and include thorough exploration of the peritoneal cavity, cytology washings, multiple peritoneal biopsies, and omentectomy. Thrall et al. (2011) mentioned that secondary surgical staging is necessary in unstaged cases of GCT; in two of eight cases, patients were upstaged. After childbearing, patients with GCTs are advised to undergo total abdominal hysterectomy and bilateral salpingo-oophorectomy with optimal cytoreduction to eliminate any residual disease. Despite the lack of prospective randomized studies, fertility sparing surgery is recommended for young women. As the incidence of bilateral disease is low (2\%) (Ranganath et al., 2008), performing a wedge biopsy on the contralateral ovary is controversial. Lymph node metastases are rarely observed in women with GCTs, therefore pelvic and para-aortic lymphadenectomy may not be included in surgical staging. Endometrial sampling is needed in women with menstrual bleeding, since up to $10 \%$ of the patients may present with endometrial hyperplasia or endometrial cancer (2\%). Patients with early-stage GCTs (stages I and II) enjoy very good prognosis with a 5-year disease-free survival rate of $89 \%$, and usually do not require postoperative treatment (Ranganath et al., 2008). Some authors suggested that patients with advanced-stage or recurrent disease might benefit from postoperative chemotherapy (Park et al., 2012; Uygun et al., 2003), but other studies found no association between the prescription of chemotherapy and improved survival rates (Al-Badawi et al., 2002; Chan et al., 2005).

Late recurrence occurs in a fraction of GCTs. In a study enrolling 93 patients, Park et al. (2012) reported that none of the patients with early stage disease submitted to optimal debulking had tumor recurrence. On the other hand, Wilson et al. (2015) found recurrent disease in $32 \%$ $(51 / 160)$ of the cases in a large retrospective series of 160 FIGO stage I AGCTs. The median time to relapse was 12 years, underscoring the typical biological behavior of AGCTs with late relapse. Due to the rarity of AGCTs, treatment options for recurrent disease have not been standardized.

This report discussed the case of a patient presented with amenorrhea and infertility. She was diagnosed with a GCT and successfully treated with surgery. Her tumor was staged as Ia disease at the time of initial surgery. Therefore, during her cesarean section she underwent fertility preserving surgery with ipsilateral salpingo-oophorectomy. Surgical staging was based on peritoneal washing 
cytology, multiple peritoneal biopsies, and omentectomy. The symptoms manifested by the patient - amenorrhea and high testosterone level - were consistent with PCOS according to the Rotterdam criteria. Initial hormonal evaluation revealed a low level of FSH (3.6 IU/I) with normal E2 level $(38 \mathrm{pg} / \mathrm{ml})$, normal AFC (10) with elevated LH levels $(22.8 \mathrm{IU} / \mathrm{l})$, mildly elevated testosterone $(68 \mathrm{ng} / \mathrm{dl})$, and very high $\mathrm{AMH}(179 \mathrm{pmol} / \mathrm{I})$ levels, all of which consistent with her initial diagnosis of PCOS.

Since clomiphene citrate (CC) is the treatment of choice to induce ovulation in women with PCOS, the patient underwent four ovarian stimulation cycles with $100 \mathrm{mg} /$ day of CC for 5 days (from day 3 to day 7) with no response, and was diagnosed with CC resistant PCOS. Clomiphene resistance - defined as failure to ovulate after receiving CC for 5 days per cycle, for at least three cycles - is a common event and occurs in approximately $15-40 \%$ of the women with PCOS (Saha et al., 2013).

The patient was not suspected for GCT, and therefore her inhibin $B$ levels were not measured. Moreover, her estradiol levels were in the low-to-normal range and never increased during stimulation cycles. When the diagnosis was confirmed (two weeks after laparoscopy), her inhibin $B$ levels were within normal range $(20 \mathrm{pg} / \mathrm{ml})$. Her AMH levels were elevated, but in the absence of other findings the increase was attributed to PCOS. It is unclear why the patient had such clinical presentation and her estradiol levels were low. Retrospectively, we suspected that her low FSH levels might be explained by possible increases in inhibin $B$ levels before surgery, since increases in inhibin B lead to declines in FSH levels (Al-Badawi et al., 2002).

The fact that her ovarian function resumed immediately after the removal of the tumor and that she was able to ovulate and become pregnant, in addition to the fact that her menstrual cycles were completely normal after delivery, suggest a potential mechanism implicating inhibin B or even AMH in clomiphene resistance.

In conclusion, this report presented the case of a patient with infertility, anovulation, and clomiphene resistance caused by a GCT without hyperestrogenism treated successfully with surgery. Further studies are required to assess the role of AMH and Inhibin B in the mechanism of clomiphene citrate resistance in women with PCOS.

\section{CONFLICTS OF INTEREST}

The authors have no conflicts of interest to declare.

\section{Corresponding author:}

Olga Triantafyllidou

Reproductive Medicine Unit

"Leto" Maternity Hospital

Athens, Greece.

E-mail: triantafyllidouolga@gmail.com

\section{REFERENCES}

Al-Badawi IA, Brasher PM, Ghatage P, Nation JG, Schepansky A, Stuart GC. Postoperative chemotherapy in advanced ovarian granulosa cell tumors. Int J Gynecol Cancer. 2002;12:119-23. PMID: 11860546 DOI: $10.1046 / j .1525-$ 1438.2002.01067.x

Bryk S, Färkkilä $A$, Bützow R, Leminen A, Heikinheimo $M$, Anttonen M, Riska A, Unkila-Kallio L. Clinical characteristics and survival of patients with an adult-type ovarian granulosa cell tumor: a 56-year single-center experience. Int J Gynecol Cancer. 2015;25:33-41. PMID: 25347095 DOI: $10.1097 /$ IGC.0000000000000304
Chan JK, Zhang M, Kaleb V, Loizzi V, Benjamin J, Vasilev $\mathrm{S}$, Osann K, Disaia PJ. Prognostic factors responsible for survival in sex cord stromal tumors of the ovary--a multivariate analysis. Gynecol Oncol. 2005;96:204-9. PMID: 15589602 DOI: $10.1016 /$ j.ygyno.2004.09.019

Chang HL, Pahlavan N, Halpern EF, MacLaughlin DT. Serum Müllerian Inhibiting Substance/anti-Müllerian hormone levels in patients with adult granulosa cell tumors directly correlate with aggregate tumor mass as determined by pathology or radiology. Gynecol Oncol. 2009;114:57-60. PMID: 19359032 DOI: 10.1016/j.ygyno.2009.02.023

Danforth DR, Arbogast LK, Mroueh J, Kim MH, Kennard EA, Seifer DB, Friedman CI. Dimeric inhibin: a direct marker of ovarian aging. Fertil Steril. 1998;70:119-23. PMID: 9660432 DOI: 10.1016/S0015-0282(98)00127-7

Fox $\mathrm{H}$, Agrawal K, Langley FA. A clinicopathologic study of 92 cases of granulosa cell tumor of the ovary with special reference to the factors influencing prognosis. Cancer. 1975;35:231-41. PMID: 1109770 DOI: 10.1002/1097-0142(197501)35:1<231: :AID-CNCR2820350128>3.0.CO;2-O

Jeong YY, Outwater EK, Kang HK. Imaging evaluation of ovarian masses. Radiographics. 2000;20:1445-70. PMID: 10992033 DOI: 10.1148/radiographics.20.5.g00se101445

Kottarathil VD, Antony MA, Nair IR, Pavithran K. Recent advances in granulosa cell tumor ovary: a review. Indian J Surg Oncol. 2013;4:37-47. PMID: 26811110 DOI: $10.1007 / \mathrm{s} 13193-012-0201-z$

Koukourakis GV, Kouloulias VE, Koukourakis MJ, Zacharias GA, Papadimitriou C, Mystakidou K. Pistevou-Gompaki K, Kouvaris J, Gouliamos A. Granulosa cell tumor of the ovary: tumor review. Integr Cancer Ther. 2008;7:204-15. PMID: 18815151 DOI: $10.1177 / 1534735408322845$

Lappöhn RE, Burger HG, Bouma J, Bangah M, Krans M, de Bruijn HW. Inhibin as a marker for granulosa-cell tumors. N Engl J Med. 1989;321:790-3. PMID: 2770810 DOI: 10.1056/NEJM198909213211204

Long WQ, Ranchin V, Pautier P, Belville C, Denizot P, Cailla $\mathrm{H}$, Lhommé C, Picard JY, Bidart JM, Rey R. Detection of minimal levels of serum anti-Müllerian hormone during follow-up of patients with ovarian granulosa cell tumor by means of a highly sensitive enzyme-linked immunosorbent assay. J Clin Endocrinol Metab. 2000;85:540-4. PMID: 10690852 DOI: $10.1210 /$ jcem.85.2.6378

Park JY, Jin KL, Kim DY, Kim JH, Kim YM, Kim KR, Kim YT, $\mathrm{Nam} \mathrm{JH}$. Surgical staging and adjuvant chemotherapy in the management of patients with adult granulosa cell tumors of the ovary. Gynecol Oncol. 2012;125:80-6. PMID: 22210469 DOI: 10.1016/j.ygyno.2011.12.442

Pectasides D, Pectasides E, Psyrri A. Granulosa cell tumor of the ovary. Cancer Treat Rev. 2008;34:1-12. PMID: 17945423 DOI: $10.1016 /$ j.ctrv.2007.08.007

Piura B, Nemet D, Yanai-Inbar I, Cohen Y, Glezerman M. Granulosa cell tumor of the ovary: a study of 18 cases. J Surg Oncol. 1994;55:71-7. PMID: 8121188 DOI: 10.1002/ jso. 2930550203 
Ranganath R, Sridevi V, Shirley SS, Shantha V. Clinical and pathologic prognostic factors in adult granulose cell tumors of the ovary. Int J Gynecol Cancer. 2008;18:929-33. PMID: 18081789 DOI: $10.1111 /$ j.1525-1438.2007.01154.x

Rotterdam ESHRE/ASRM-Sponsored PCOS Consensus Workshop Group. Revised 2003 consensus on diagnostic criteria and long-term health risks related to polycystic ovary syndrome. Fertil Steril. 2004;81:19-25. PMID: 14711538 DOI: $10.1016 /$ j.fertntert.2003.10.004

Saha L, Kaur S, Saha PK. N-acetyl cysteine in clomiphene citrate resistant polycystic ovary syndrome: A review of reported outcomes. J Pharmacol Pharmacother. 2013;4:18791. PMID: 23960423 DOI: 10.4103/0976-500X.114597

Schumer ST, Cannistra SA. Granulosa cell tumor of the ovary. J Clin Oncol. 2003;21:1180-9. PMID: 12637488 DOI: $10.1200 / J C O .2003 .10 .019$

Thrall MM, Paley P, Pizer E, Garcia R, Goff BA. Patterns of spread and recurrence of sex cord-stromal tumors of the ovary. Gynecol Oncol. 2011;122:242-5. PMID: 21481441 DOI: $10.1016 /$ j.ygyno.2011.03.020
Ugianskiene A, Grove A, Soegaard-Andersen E. Adult granulosa cell tumor of the ovary: a retrospective study of 37 cases. Eur J Gynaecol Oncol. 2014;35:621-4. PMID: 25556264 DOI: 10.12892/ejgo25612014

Uygun K, Aydiner A, Saip P, Kocak Z, Basaran M, Dincer M, Topuz E. Clinical parameters and treatment results in recurrent granulosa cell tumor of the ovary. Gynecol Oncol. 2003;88:400-3. PMID: 12648593 DOI: $10.1016 / S 0090-$ 8258(02)00141-5

Wilson MK, Fong P, Mesnage S, Chrystal $K$, Shelling A, Payne K, Mackay H, Wang L, Laframboise S, Rouzbahman M, Levin W, Oza AM. Stage I granulosa cell tumours: A management conundrum? Results of long-term follow up. Gynecol Oncol. 2015;138:285-91. PMID: 26003143 DOI: 10.1016/j.ygyno.2015.05.011

Zahid N. Role of Anti-Mullerian Hormone (AMH) in Polycystic Ovary Syndrome (PCOS)? A Mini Review. Reprod Syst Sex Disord. 2014;3:143. DOI: 10.4172/2161-038X.1000143

Zhang M, Cheung MK, Shin JY, Kapp DS, Husain A, Teng NN, Berek JS, Osann K, Chan JK. Prognostic factors responsible for survival in sex cord stromal tumors of the ovary--an analysis of 376 women. Gynecol Oncol. 2007;104:396400. PMID: 17030354 DOI: $10.1016 /$ j.ygyno.2006.08.032 